\title{
An Urgent Call for I-O Psychologists to Produce Timelier Technology Research
}

\author{
Jerod C. White ${ }^{1}$ \\ Daniel M. Ravid ${ }^{2}$ \\ Ian O. Siderits ${ }^{3}$ \\ Tara S. Behrend ${ }^{1}$ \\ ${ }^{1}$ Purdue University \\ ${ }^{2}$ The George Washington University \\ ${ }^{3}$ North Carolina State University
}

Pre-print version of an in press, accepted manuscript. Please cite as:

White, J. C., Ravid, D. M., Siderits, I. O., \& Behrend, T. S. (2021, in press). An urgent call for IO psychologists to produce timelier technology research. Industrial and Organizational Psychology.

\section{Acknowledgements:}

We would like to thank Allie Huyghe for her assistance in generating the SIOP timeline used in this study.

\section{Correspondence author:}

Jerod C. White

Purdue University, 703 Third Street

West Lafayette, IN 47907

Contact: jerodcw@gmail.com 


\begin{abstract}
The rapid pace at which technology changes creates a challenge for I-O psychologists, who often conduct hypothetico-deductive research. In this article, we examine technology research in the IO psychology community by asking three questions: "Why should I-O psychologists study new technologies?," "How timely is I-O psychologists' technology research?," and "How can I-O psychologists produce timelier technology research?" Using archival data from 23 years of SIOP conferences and a historical timeline of technology innovations, we find that I-O psychologists study technology milestones an average of 6.10 years after they first enter widespread awareness and adoption. We discuss the implications of this lag and conclude by urging I-O psychologists to study technology with an eye toward action, exploration, collaboration, dissemination, and creation.
\end{abstract}

Keywords: Technology; Inductive Research; Exploratory Research; SIOP 


\section{An Urgent Call for I-O Psychologists to Produce Timelier Technology Research}

In March 2020, millions of workers abruptly shifted their jobs from familiar offices and cubicles to an uncertain and socially distanced cyberspace. The COVID-19 pandemic transformed the world in considerable ways, and technology remained core to many of these changes. At a time when workers across the globe faced immense uncertainty, business leaders used technology to connect their physically separated workers and to fuel the economy to the extent possible. Many industrial-organizational (I-O) psychology scholars responded to the crisis by disseminating their research in easy-to-access formats with hopes of aiding organizations in need (e.g., see Butina's (2020) podcast on coaching leaders, Curphy and Nilsen's (2020) white paper on managing stress; or Rogelberg's (2020) video on conducting remote meetings). Still, many I-Os found themselves scrambling to understand technology-related issues during the crisis (e.g., employee reactions to remote monitoring, Morrison, 2020; work-life balance in telework, Grant, 2020; transitioning to a virtual academic conference, Landers, 2020). Ideally, the I-O community would have been ready to respond to this crisis because we had built an understanding of virtual work - but in many cases our knowledge base was insufficient.

The goal of this paper is to encourage I-O psychologists to take a proactive approach to studying technology that supports our duty to address dynamic workplace issues. Some issues, like the recent shift to virtual work, occur rapidly and without much notice. Other issues, like concerns regarding the automatability of jobs, have unfolded gradually as new technologies are introduced into the workforce. In either case (sudden or gradual change), I-O psychologists are expected to apply "principles of individual, group, and organizational behavior ... to the solution of problems at work (American Psychological Association, 2008). This expectation communicates a clear duty for our research community to not only understand how technology 
influences modern workers, but also to resolve the challenges they may face as a result of technological change. Meeting this expectation therefore requires our field to study new technologies in a timely manner.

Technologies directly influence individuals' work behaviors, attitudes, perceptions, and cognitions. This is true both in times of crisis and prosperity. Many people who began working remotely because of COVID-19 reacted to their new work environments with a sense of frustration, while others expressed confusion or even gratitude (Holmes, 2020). From a behavioral perspective, these workers also found new ways to complete their jobs (e.g., online doctor consultations, Abelson, 2020), socialize with coworkers (e.g., virtual happy hours, Overland \& Jarvis, 2020), and even slack off (e.g., doing housework, Liang, 2020). Technology further influences how individuals conceive of time and space (Harvey, 1989), and in the context of shifting to remote work, the boundaries between when and where work should take place are blurred (Shockley \& Clark, 2020). Similar effects occur for other technologies and during less extreme times as well. Throughout the late 1990s and 2000s, for example, virtual reality advancements allowed some workers to learn job-relevant skills and communicate with others in ways previously not possible (Pierce \& Aguinis, 1997). Changes such as these are inevitable; organizations will always be in a position to adopt new technologies.

Because technology profoundly impacts work and workers, it also influences the attitudes, behaviors, and cognitions that I-O psychologists study. For example, the classical scientific management approach to studying worker efficiency now lacks relevance in part because technology has replaced many jobs suited for time-and-motion studies. For a timelier example, consider worker attitudes and behaviors related to privacy. A Google Scholar search of “worker privacy” yields 74 results published between 1980 and 1990, 180 results published 
between 1990 and 2000, 319 results published between 2000 and 2010, and 504 results published between 2010 and 2020. These steady increases are not surprising, given that organizations adopted now-ubiquitous technologies such as the computer, the Internet, and digital monitoring tools during that time. Such tools transformed the ways workers think and behave in their jobs, therefore shaping the kinds of questions we ask as researchers.

I-O psychologists spend a great deal of time developing theories about employee attitudes, behaviors, and cognitions. Some scholars have noted that I-O psychology is distinct from other social science fields in its strong preference to develop theories before observing facts (Hambrick, 2007). The domain of technology is unique in that it experiences change at an exceptionally fast rate. For this reason, some I-O psychologists have argued that building unifying, longstanding theories of technology is quite challenging (Landers \& Behrend, 2017).

Without making changes to our research approach, I-O psychologists are at risk of falling behind in understanding the psychological effects of new technologies. Our aim in this focal article is to encourage timelier research of new technologies in the I-O psychology community. We do so by answering three questions. First, we ask, "Why should I-O psychologists study new technologies?" with a particular focus on how technology shapes outcomes of interest to I-O psychologists. We then ask, "How timely is I-O psychologists' technology research?" using data from the past 23 years of Society of Industrial and Organizational Psychology conferences to formulate an estimate. Finally, we close by asking, "How can I-O psychologists produce timelier technology research?," and in the process, we offer five concrete recommendations to our field.

\section{Why Should I-O Psychologists Study New Technologies?}

To demonstrate technology's effects on workers, we first adopt Morelli, Potosky, Arthur, and Tippins' (2017) definition that technology is "the constellation of individual tools that assist 
a user with controlling or adapting to his or her environment" (pp. 336). Many definitions of technology exist; we chose this definition because it encompasses both general (i.e., “constellation"; e.g., crowdsourcing) and specific (i.e., "individual”; e.g., MTurk) classifications of the digital tools or practices used in organizations. In this paper, we highlight specific tools to illustrate that individual technologies can influence work outcomes, but we also consider the implications of these specific tools as they relate to their more general technological classifications.

In addition, we adopt Gartner's Hype Cycle as a framework to organize our examples temporally ("Hype Cycle," n.d.). While the framework lacks rigor as a standalone theory (Steinert \& Leifer, 2010), it offers a valuable description of the lifespan of workplace technologies. That is, most widely adopted technologies begin with some sort of breakthrough that sparks public interest (i.e., an innovation trigger), which thus intensifies public expectations about the technology's potential. These expectations are typically left unmet in the short term (i.e., a trough of disillusionment). Over time, users realize the benefits of the technology (i.e., a slope of enlightenment), which ultimately leads to a more universal, long-term acceptance of the tool (i.e., a plateau of productivity). See Figure 1 below for Gartner's graphical representation of the cycle. Each technology represents a unique case that may be misaligned with the cycle's general propositions. Technologies can withstand several peaks or troughs, and some may never reach a plateau of productivity. In this regard, we employ the cycle as a descriptive, rather than prescriptive, tool for distinguishing among those technologies that acquire widespread adoption and those that do not. 
Importantly, a new technology will influence outcomes of interest to I-O psychologists regardless of its position in the Hype Cycle. Whether a workplace tool is in its early innovation trigger stage, at a peak of inflated expectations, in a trough of disillusionment, or in a plateau of productivity, it can shape employee thought or behavior in meaningful ways for I-O psychologists to understand.

Some technological inventions go on to become ubiquitous and present scholars with many research opportunities. For example, Skype was released in 2003, allowing users to communicate online via synchronous phone and video calls in a more user-friendly manner than similar prior programs allowed (e.g., CU-SeeMe; Todd, 1996). As a result, many organizations started using the service to connect employees to each other and to clients in a cost-efficient manner (Simmons, 2005). At that time, I-O psychologists needed to understand how this tool was changing how workers thought and behaved in their jobs. For example, interviewees' traditional impression management tactics were changing (e.g., physical handshakes were not possible via video), and workers were becoming increasingly wary of their privacy online (Greene, 2008; McCullagh, 2008). The videoconference showed clear potential to shape employee thought and behavior at its popularization in the early 2000s, prompting a number of valuable research questions for I-O psychologists to explore. These questions have remained important as new videoconference programs emerge (e.g., Zoom). Other technologies, such as social media and the Internet more generally, have followed a similar lifespan toward ubiquity and now influence workers across the globe.

Even technologies that never reach a plateau of productivity can influence workers and therefore provide learning opportunities for I-O psychologists. For example, Google Lively was 
a web-based virtual community platform launched in July 2008 that allowed users to share virtual worlds, chat, and exchange photos or videos with one another. The public highly anticipated Google Lively, but by December 2008 it was discontinued (Huvila, 2015). Despite its short lifespan, early news reports reflected a favorable change in the public's perception of virtual worlds, with one article predicting that Google Lively would usher in a new era of telecommuting (Elgan, 2008). Documented cases of businesses using Google Lively are limited, but anecdotal (Dean, 2020) and empirical (Pearlman \& Gates, 2010) evidence suggests that virtual world meetings were awkward, impractical, or stress-inducing for those who experienced them. Importantly, these effects presented I-O psychologists with opportunities to advance several theories in the field, including those related to communication and teamwork. Other technologies, such as 3D-enabled devices (e.g., televisions) have similarly faded into obscurity but nonetheless showed potential in exploring work-related research questions (e.g., how to create an immersive learning environment).

Other technologies follow an unpredictable path in Gartner's lifecycle but nonetheless provide I-O psychologists with research opportunities at each stage. Consider Google Glass, and an eyeglass-shaped augmented reality (AR) device introduced in February 2013 that allowed users to search the Web, capture photos and videos, and access third party apps in a mostly hands-free manner. The general public reacted favorably, and Google eventually launched its “Glass at Work” program with partners who created AR business apps (Kastrenakes, 2014). Around this time, I-O psychologists had many research opportunities, as employees wearing Google Glass were expressing privacy concerns while interacting with others (Bell, 2014). By January 2015, Google stopped producing the device. Interestingly, the device made its return to organizations in 2017 and continues to serve as an assistive tool for those working in the 
manufacturing, logistics, and healthcare industries (Google.com/glass, 2020). For I-O

psychologists, many research questions about AR wearables and their effects (e.g., on job performance, wellbeing, and privacy) have remained unanswered throughout the technology's introduction, decline, and recent resurgence in organizations. The recent COVID-19 pandemic may soon provide more examples of technologies making a return-QR codes, for example, have grown in popularity recently as businesses seek to minimize physical contact among workers and customers (Rivero, 2020).

\section{How Timely is I-O Psychologists' Technology Research?}

Having demonstrated that the introduction of technologies to workplaces (widespread or otherwise) present valuable research opportunities for I-O psychologists, we now turn to an assessment of I-O psychologists' research coverage of technology. Thus far, we have discussed many news reports that portray workers' and the general public's reactions to new technologies. These reports capture the human tendency to adopt "shiny object" fallacies that ChamorroPremuzic and colleagues (2016) described as leading working professionals to sometimes adopt new tools without fully understanding their effects. A growing concern among I-O researchers is that we also lack an understanding of "how" and "why" new technologies affect employees (Chamorro-Premuzic et al., 2016; Morelli et al., 2017). As I-O psychologists, our duty is to prevent new technologies from producing unwanted effects and instead help organizations keep their employees happy, motivated, and productive. Achieving this duty requires us to embrace the uncertainty of studying new technologies in order to truly understand employees in the modern workforce. The present study explores these concerns by measuring the amount of time that unfolds between when a workplace technology is introduced and when I-O psychologists study it for the first time. 


\section{Procedure}

We considered a variety of data sources for this investigation, each ranging in academic rigor and timeliness. Peer-reviewed publications in I-O psychology journals represent the most rigorous, yet least timely, source. The peer-review process for journal articles, despite ensuring quality research in our field, can take years to unfold and represents a poor measure of when I-O psychologists actually study a given technology. The other extreme is social media discussions among I-O psychologists, which represents a timely, yet questionably rigorous, source. Many members of our field use platforms like Twitter to exchange ideas about hot topics in I-O psychology, but many of these discussions are speculative and lack evidence. In the middle of these extremes are conference presentations, which include a peer-review process but are much more timely than academic journal articles. Further, SIOP submissions reflect a desire to share one's knowledge with peer I-O psychologists, representing a signal that the topic of these submissions is important in the I-O community. In contrast, both journals and social media are intended to influence others at large, without a clearly defined audience for the most part. As such, we chose to study the timeliness of I-O technology research in conference presentations at SIOP.

The Society of Industrial Organizational Psychology (SIOP) annual conference represents the largest gathering of I-O psychologists, and the content of each year's program represents the topics predominating the field at a given point in time. As such, the year that a work-related technological innovation first appears on a SIOP conference program should fairly accurately represent when that innovation entered the I-O psychology discourse. Examining the difference between when technological innovations are created or popularized (i.e., “technological milestones"), and when they appear on a SIOP conference program can thus 
provide quantitative evidence of whether I-O psychologists are truly lagging in producing timely technology research.

We used archival data analysis techniques to investigate the timeliness of technology research in SIOP by first generating two separate timelines. The first, the History of Technology (HoT) timeline, represents a compilation of five separate timelines of technology: the Technology Timeline from datesandevents.org, the Technology Through the Years timeline from King University, the Timeline of Computer History from the Computer History Museum, the Selected History of DARPA Innovation timeline from DARPA, and the Hobbes' Internet Timeline 25 by Robert Hobbes' Zakon. Additions to the HoT timeline were made on a case-bycase basis when workplace technologies were not mentioned in the five primary sources. Additional sources included MIT's Technology Review, the Museum of Arts and Design's 3D Printing Timeline, and product or service websites (e.g., Fitbit.com, Uber.com, Skype.com). For any remaining cases, we used peer-reviewed articles found on Google Scholar to identify the year for which a specific workplace technology was first introduced. Across all of these sources, most data points indicated when a technology was first invented (e.g., social media) or when a technology-related word was first coined (e.g., Internet of Things). Other sources provided data points that indicated when a technology was popularized or became commercially available (e.g., GPS). The final HoT timeline included over 1,500 data points related to technological milestones from 2400 BCE to present day. ${ }^{1}$

The second timeline, the SIOP timeline, includes a comprehensive list of technologyrelated submissions over the last 23 SIOP conferences. The researchers manually reviewed all public SIOP Annual Conference programs available on SIOP's website, which included 23

\footnotetext{
${ }^{1}$ The History of Technology timeline is available in an online supplement at the following link: https://osf.io/jm6f4/?view_only=1a6a42751a5f4544866ed714966ddbc7
} 
programs between 1998 and 2020. Researchers reviewed each program for any posters, symposia, panel discussions, or other submissions that related to technology concepts. Symposia, practitioner forums, and other special events containing multiple papers about technology were further sorted; any non-technology related submissions in multi-paper events were omitted from the SIOP timeline. ${ }^{2}$

Any submission whose technology relevance was under question was highlighted in the timeline and reviewed by two researchers; cases in which both reviewers agreed that a submission lacked relevance were removed. The researchers then determined which submissions were also identified in SIOP conference programs as being related to technology. Physical copies of conference programs were reviewed to ensure accuracy in SIOP's online programs. For example, the submissions listed online for 2001 contained only one item tagged for technology, while the physical copy listed 76 items. Additionally, a select few items marked as technologically relevant in the SIOP programs were not included in the SIOP timeline because the researchers did not agree that these items were relevant. ${ }^{3}$ All remaining submissions were reviewed for inclusion in the final SIOP timeline, which included 2,365 technology submissions from 1998 to 2020.

We identified 48 technology milestones since 1998 with work-related implications from the HoT timeline. ${ }^{4}$ For milestones related to the invention or popularization of a broad family of

\footnotetext{
${ }^{2}$ The SIOP technology research timeline is available in an online supplement at the following link: https://osf.io/jm6f4/?view_only=1a6a42751a5f4544866ed714966ddbc7

${ }^{3}$ Some submissions' abstracts contained insufficient information to conclude their technology relevance, such as one 2005 community of interest session without an abstract titled Grant Writing. Other submissions focused on topics whose technology relevance was sometimes ambiguous, such as those about data. For example, one datarelated submission discussed storytelling using data but did not mention any specific technological tools or methods (Adler, Nelson, \& Grubb, 2020); this submission was not included in the SIOP timeline. Other related submissions explicitly discussed data science tools like R and SQL and were thus included in the SIOP timeline (e.g., Auer, Collmus, \& Kaminsky, 2020).

${ }^{4}$ The 48 technology milestones and their corresponding SIOP submissions (or lack thereof) are available in online supplements located at the following link: https://osf.io/jm6f4/?view only=1a6a42751a5f4544866ed714966ddbc7
} 
technologies (e.g., social media; virtual reality headsets), we calculated the average of the years for which specific technologies were introduced (e.g., Facebook and Twitter; Occulus Rift and HTC Vive). Of these 48 milestones, 40 had been studied at least once at a SIOP conference. To identify the first SIOP submission for a given milestone, the researchers searched the SIOP timeline for keyword variations of the milestone. For example, for the popularization of wearable devices, we included keyword searches for "wearable," "tracker," "smartwatch," "Fitbit," and "Apple Watch" to find the earliest SIOP submission discussing the milestone.

To analyze the data, a difference was calculated for each milestone using its years on the HoT and SIOP timelines, respectively. This difference represents the lag in I-O psychology research on a given technology. To better interpret each lag, we also explored the format of submissions (e.g., posters, symposia, etc.) across all first mentions associated with the milestones.

\section{Results}

Our results show that on average, technological milestones are first discussed at the SIOP conference 6.10 years $(S D=4.47)$ after they occur. As a follow-up analysis, we investigated whether these mean differences grew smaller, larger, or remained the same over time. To do so, we divided technological milestones across three time periods. A large proportion of the 40 milestones occurred during the first few years of the SIOP timeline, so we selected intervals based on equal numbers of observations rather than equal numbers of years. Each interval (i.e., 1998-2001, 2002-2005, and 2006-2020) contained either 13 or 14 observations, allowing for a more representative comparison of means. Results show that in 1998-2001, there was an average lag of 7.08 years $(S D=5.69)$. This average lag decreased to 6.31 years $(S D=4.09)$ in $2002-2005$, and it decreased again to 5.00 years $(S D=3.51)$ in $2006-2020$. 
Across the 40 technological milestones, we found 54 SIOP submissions that represented a "first" investigation. Seven milestones (i.e., essay scoring, autonomous robots, social media, Big Data, deep learning, gig economy, and wearables) were mentioned in more than one submission in the year they first entered our SIOP timeline. For example, there were eight submissions on Big Data in 2014, the year it first appeared in our timeline. Of the 54 first submissions, $29.63 \%$ were posters, $22.22 \%$ were symposia, $12.96 \%$ were special events, $11.11 \%$ were panel discussions, $7.41 \%$ were practitioner forums, $3.70 \%$ were roundtable discussions, $3.70 \%$ were master tutorials, $1.85 \%$ were alternative sessions, $1.85 \%$ were education forums, and $1.85 \%$ were debates.

\section{Discussion}

We found that SIOP members discuss technological milestones an average of 6.10 years after they have occurred, and this lag appears to have decreased over time. On average, SIOP members were slower to study the first third of the technological milestones (i.e., those occurring in 1998-2001) than they were with more recent technological milestones (i.e., those occurring in 2002-2005 and 2006-2020). However, we also identified eight work-related technological milestones that have never been covered at SIOP conferences (e.g., "coworking," 3D printing). Seven of these unstudied topics occurred during the final third interval of our data, meaning that the actual timeliness of I-O psychologists' research for the 2006-2020 interval may be slower than five years. To illustrate, consider the hypothetical scenario in which I-O psychologists investigated all of the unstudied topics at the 2021 conference. If this were the case, the new average lag for technological milestones occurring between 2006 and 2021 would be 6.62 years, which is comparable to the 2002-2005 lag. Still, such a scenario is unlikely, and as a result, this 
study offers preliminary evidence that I-O psychologists are beginning to produce timelier technology research at SIOP.

There are several possible explanations for the decreased lag we observed. Perhaps the most obvious is the increasing size of the SIOP community since 1998. According to the SIOP website, there were around 2,500 conference attendees in 1998. This estimate more than doubled to 5,348 attendees in 2019. With more attendees, one would expect greater diversity among members, and in turn, more diverse interests in the community. Another explanation is that that the number of journal outlets and the interests of those journals has broadened, thus opening up more opportunities to engage in technology research. Indeed, some I-O related journals now explicitly list technology as a desired subject matter of their papers, and others have recently called for special issues on technology-related topics. Yet another explanation for the reduced lag concerns the general history and evolution of I-O psychology. As the field has grown, I-O psychologists have established a body of knowledge that is mature and thus it is more difficult to make a transformational contribution in those areas. While some have urged new researchers to study established I-O topics (Campion, 2011), it is worth noting that technology topics tend to emerge and present a variety of new opportunities for researchers wishing to make a name for themselves. Collectively, these incentives have likely encouraged I-O psychologists to engage in more technology research in recent years.

The variation in formats across first submissions provides some indication of the kinds of research I-Os have conducted on new technological milestones. Over half $(51.85 \%)$ of first submissions were posters or symposia, and these formats typically represent empirical investigations of psychological phenomena. Thus, I-Os seem to gather data a substantial amount of the time when studying new technologies. It is particularly interesting to note that symposia, 
which involve multiple researchers coming together to present their work on a similar topic, represented the first submission for several technological milestones. For example, the first submission for text analysis was a symposium titled Automated Text Analysis in I-O Psychology: Research to Practice which included papers from researchers at four different institutions sharing their work on the topic. It appears that I-O psychologists had been conducting research on text analysis for some time before presenting it at SIOP. The rest of first submissions were less empirical, such as practitioner forums or roundtable discussions. Non-empirical formats may be particularly useful for introducing scholars to new research areas for which theory or a conceptual understanding is lacking. For example, one theme track session was described as a TEDstyle talk that presented information about new technologies to attendees in a "digestible, engaging manner" that would perhaps not be possible with other formats (Waber, Impelman, \& Shockley, 2014). Collectively, the variability in first submission formats seems to suggest a balance in I-Os' empirical and non-empirical investigations of new technologies.

While the decrease in lags over time is encouraging, we should note that a sizable lag exists across every interval of our timeline. Even the most recent lag estimate of five years, while smaller than the earlier estimates, demonstrates a general deficiency in I-O psychologists' coverage of new technologies. To better contextualize what our average lag estimates mean for IO psychologists, let us consider technologies individually. We will begin by describing findings regarding the three technologies discussed in the introduction (i.e., videoconferences, virtual worlds, and augmented reality wearables), then turn to a discussion of other noteworthy technologies.

For videoconferences, I-O psychologists actually studied the technology before its popularization in organizations. While videoconferencing was popularized in 2003 in part due to 
the launch of Skype, we identified a 1998 poster that investigated videoconferencing software in the employment interview (Chapman \& Rowe, 1998). The study investigated organizations using similar software available at the time, finding that videoconference interviews were less effective for recruiting than other media. In addition to this study, a 1999 symposium discussed the challenges and opportunities associated with videoconferencing for team collaboration (Offermann \& Eller, 1999), a 1999 poster investigated gender differences in videoconference negotiations (Graetz et al., 1999), and a 2002 poster explored applicant reactions to videoconference interviews (Quintero \& Strickland, 2002). The timeliness and abundance of this research is aligned with the generally favorable public reactions to videoconferences since 2003. Science and practice should ideally inform one another: In the case of videoconferences, I-O psychologists were prepared to inform organizations in their decision to use (or not use) the technology in the early 2000s.

With a lag of seven years, virtual worlds received less timely research from the I-O community. This technology was popularized in part due to the creation of World of Warcraft in 2004, yet a 2011 symposium about its uses in recruitment, training, and teamwork was the earliest SIOP presentation we identified on the topic (Landers \& Behrend, 2011). The following SIOP presentations on the topic came several years later, with a 2017 presentation exploring virtual world assessment (Short et al., 2017) and a 2018 poster exploring virtual world training (Goh et al., 2018). This apparent lack of research from the I-O community did little to inform the decisions of those who adopted virtual worlds for work in the late 2000s. While I-O psychologists are not solely responsible for the short-lived use of virtual worlds in certain contexts (e.g., in meetings; Pearlman \& Gates, 2010), more research on the technology could have helped organizations use the tool more effectively and thus facilitated a broader adoption. 
Augmented reality wearables have received little to no attention from I-O psychologists at SIOP conferences. These devices were popularized in 2012 in part due to Google Glass, yet we identified no SIOP presentations with the phrases "Google Glass" or "augmented reality wearable" in the title or abstract. We did identify four studies about AR more generally (Keebler, 2017; Keeneyet al., 2020; Roberts, 2018; Sydell et al., 2017), but the earliest of these was presented in 2017. Further, most of these were sessions in which I-Os reviewed the history or theorized about the future of AR training without conducting new empirical investigations of the practice. Such theorizing can indeed be useful, particularly for guiding subsequent research on technologies that are new or challenging to study. Moving beyond conceptual sessions toward more empirical sessions may require collaborations and partnerships, which we discuss further in the Collaboration section below. Encouragingly, Keeney and colleagues' (2020) poster about estimating the value of virtual, augmented, and mixed reality tools in training seems to represent an early empirical investigation into AR at work. Still, several gaps still remain in understanding AR's work-related psychological effects. In light of Google Glass' resurgence in organizations, I-O psychologists may soon find themselves rushing to collect empirical data that can resolve any unforeseen (or foreseen, i.e., privacy invasion) issues the technology presents.

Across various technologies, it appears that I-O psychologists are often slow to study technologies that are created for non-work purposes. For example, there were notable lags for some technologies marketed toward gamers (e.g., virtual worlds) and everyday consumers (e.g., social media). To I-O psychologists, the work-related implications of such technologies may not be immediately clear. Indeed, we found it somewhat challenging to select tools for inclusion in our unstudied technologies timeline because there are many tools that could have work-related implications, despite their absence from many white-collar workplaces (e.g., 3D printers, 
drones). As technological advancements continue to occur in various industries (e.g., gaming, transportation, engineering), I-Os will need to look outside of the traditional organizational context if they wish to study work technologies in a timelier fashion.

Changes at the within-technology level of analysis are also worth addressing. Consider wearable devices, which had a lag of five years between their popularization and I-O psychologists' first empirical investigation. It is unwise to assume that an employee's wearable device in 2009 possessed the same capabilities as an employee's wearable device in 2014. For example, the first Fitbit device allowed users to track their movement, sleep patterns, and calories burned but was not smartphone-connected. By 2014, the device acquired new features such as continuous heart rate tracking and passive phone-based tracking. Employees using the 2014 Fitbit could have exhibited different privacy concerns than those using the original Fitbit, though hypotheses such as this remain untested. Functional changes to a tool over time can affect employees in different ways, and these changes necessitate timely research from I-O psychologists much like newly introduced tools.

In addition to discrete technologies, we also included several "buzzwords" and trending topics in our analysis. Buzzwords and trending topics are distinct from individual technologies in that they reflect a broader, socially driven interest in a given tool or practice. For example, “social media influencer" represents a new job that many individuals now find lucrative by virtue of new technologies (e.g., social media, livestreaming). Perhaps unsurprisingly, I-O psychologists waited nine years to formally study this job after its coining in 2011 (Bricka et al., 2020; Freberg, et al., 2011). Or, consider "Big Data" as another example. While specific technological inventions supported the existence of Big Data (e.g., smartphones, wearables, data analysis software), the phrase was not coined until 2005 when researchers recognized just how 
large and powerful their datasets were becoming (Emani et al., 2015). In this way, it is interesting that it also took I-O psychologists nine years to first explicitly cover the topic at the conference (e.g., Levine, 2014). Members of our community had certainly been discussing social media influencers and Big Data indirectly leading up to those presentations. In particular, the I-O community clearly had an interest in incorporating Big Data in their own research projects and practices leading up to 2014 , as made evident by the eight submissions in the year it finally entered the SIOP timeline. Even so, informal discussions about new technologies do little in comparison to explicitly tagged sessions when it comes to capturing the attention of professionals who can benefit most from our research. Without easily identifiable research, we make it challenging for people to make informed decisions regarding trending technology topics.

Encouragingly, I-O psychologists have produced timely research for some technologies over the past two decades. Our field's involvement in developing the O*NET database, for example, helped ensure that job seekers and HR professionals had reliable data to inform their work decisions when it was released to the general public in 1998 (e.g., Kubisiak et al., 1998). Further, I-O psychologists studied virtual reality headsets and identified their uses and misuses in training long before they were widely commercialized (e.g., Fletcher et al., 2000). I-O psychologists also had wisdom to share about unproctored internet testing before the COVID-19 crisis when the vast majority of the world's students shifted to online learning environments (e.g., Landers \& Sackett, 2009; Scarborough et al.,2006). For all of these technologies and several others, I-O psychologists studied a new tool before or around the same time as its invention or popularization, a favorable situation that allowed us to lead the way in advising organizations during adoption.

\section{Limitations and Future Research}


Several limitations of this archival analysis are worth noting. Although 23 years' worth of research encompasses several major technological milestones, SIOP conferences date another 12 years before 1998. Our HoT timeline includes hundreds of data points related to technological milestones before 1998 (e.g., popularization of the computer and the Internet; coining of digital practices like "affective computing" and "electronic performance monitoring"), but we were unable to estimate these lags without access to earlier programs. Additionally, we chose to overcome errors associated with automatic keyword searches by manually searching existing technology timelines and SIOP conference programs. To minimize the influence of human error and bias on our analyses, we involved multiple researchers at each stage while creating the HoT and SIOP timelines. Even so, the 2,365 identified SIOP presentations we identified might not represent a perfectly comprehensive set of relevant studies. Similarly, the 48 data points generated from existing technology timelines and empirical research may reflect the researchers' biases. It remains possible that our analysis overlooked work-relevant technologies or included technologies with limited relevance. We encourage members of the I-O community to refine and expand upon this list with relevant technologies used in their own subdomains of study.

We generated a dictionary of keywords, and we recognize that some of these dictionaries may have been imperfect. However, we feel this conceptualization of "first instance" is appropriate given that papers that do not use the keywords in our dictionary would not be discoverable by other researchers and therefore would not be contributing to the knowledge base of this topic. Our online SIOP timeline provides a variety of data points, such as submission titles, abstracts, and format types, which allows for further investigations of technology research in the community. We encourage interested readers to browse this timeline to develop their own research questions related to I-Os' technology research. 


\section{How Can I-O Psychologists Produce Timelier Technology Research?}

Identifying the presence of a lag does little to advance our field of study. As such, we now turn to a broader discussion regarding the nature of our research lag and lessons to learn from it. To do so, we propose five recommendations for I-O psychologists to produce timelier research, each addressing unique challenges that may explain why the 6.10-year lag currently exists.

\section{Action}

I-O psychologists should strive to study new technologies as they are created, and to imagine possible workplace applications, not wait until they are widely adopted. In other words, we should choose action over cautiousness when it comes to studying new technologies. As we are all researchers with limited resources (e.g., time, funding), this recommendation may seem to come from a place of luxury, in that this approach involves risk. There is indeed an inherent risk associated with studying a new tool that may later fade into obscurity, whereas studying a widespread tool ensures that our research is more relevant to a larger audience. However, we urge the field to push back against this way of thinking for two related reasons.

First, I-O psychologists can learn as much from new technologies that are rejected as we can from those that gain widespread adoption. We cannot predict with any certainty which new technologies will eventually gain mass adoption, but this should not stop us from studying them. Any technology that enters organizations_-regardless of its long-term lifespan—will influence outcomes of interest to I-O psychologists. Virtual worlds were, by many regards, a fad technology, but one that still presented I-O psychologists with useful research insights (Pearlman \& Gates, 2010). Further opportunities existed to expand and identify boundaries of existing theories related to communication, teamwork, or workplace privacy. Some other technologies, 
like videoconferencing software, sustain moderate influence until some environmental shock stimulates sudden widespread adoption. In these scenarios, early research on a new technology enables us to be informed about its uses and misuses when high-demand or crisis situations arise. In either case (fad or mass adoption), we have much to gain from a learning perspective when studying new workplace technologies.

Additionally, I-O psychologists can use the introduction of a new technology as an opportunity to capture its unique effects as it enters the workplace. Such scenarios represent an ideal condition for conducting fundamental A-B intervention studies that would not be feasible for older, more established technologies. The effects of new technologies are undoubtedly dynamic; they will interact with novelty effects, social contexts and norms, and perhaps, the effects of previous work processes that the technology is supplementing or replacing. Waiting for the widespread adoption of a technology is failing to capture these initial interactive effects that are very likely to change over time.

\section{Exploration}

In order to produce timely technology research, I-O psychologists must be comfortable conducting exploratory, inductive, and abductive technology research (Woo et al., 2017). From hypothesis generation to data collection and analysis, the typical timeline of a hypotheticodeductive research study — wherein a proposed or existing theoretical model must precede observation - may span multiple years. In this case, I-O psychologists may very well study new technologies shortly after they are introduced or popularized, but they are unable to complete or disseminate their research in a timely manner. Our archival analysis offers some support for this explanation, with only 11 studies explicitly described as "inductive" or "exploratory" in the title or abstract (Bowen, et al., 2019; Brown, et al., 2001; Haidar et al., 2020; Lim et al., 2008; 
McManus \& Ferguson, 2002; Paik et al., 2013; Rosopa et al., 2020; Scarborough \& Somers, 2008; Vandenberg \& Connelly, 2014; Woo, 2020; Wright \& Gloss, 2015).

Given the pace with which technologies advance and the relative infancy of technology research, relevant psychological theory to succinctly explain the effects of many new technologies often does not yet exist. For instance, organizations are increasingly using high fidelity virtual reality and augmented reality technologies to train (Gasparevic, 2018), assess (Nassauer \& Cutter, 2019), and even socialize (Reuter, 2020) employees. Suitable theory to explain how varying levels of immersion and fidelity should influence variables of interest like learning and performance trajectory has yet to be formulated (Bowman \& McMahan, 2007; Cummings \& Bailenson, 2016). Trying to root these kinds of research questions in tenuously connected existing psychological theory will not only frame research within mis-fit models, but it will also slow the formulation of new better fitting theory (Locke, 2007). Further, waiting to test questions for which we already have mature theory will leave critical research questions about technologies and work in the hands of those less equipped to answer them.

Importantly, conducting inductive technology research does not imply an absence of theory. As a constantly evolving object of study, technology lends itself to the creation of theoretical frameworks as opposed to theoretical models. While frameworks generally describe or organize groups of objects, models mathematically assert the interrelationships of constructs. It is challenging to develop models of technology because doing so forces us to assume that technology is a construct with a unifying causal structure (Landers \& Behrend, 2017). Such an assumption is tenuous given that so many families of technologies exist, and technologies regularly change in ways that make their precise measurement difficult. Of greater interest to I-O psychologists is an understanding of the psychological effects of technologies, and as such, 
technology is better conceptualized as a boundary condition or stimulus of psychological theories. Several technology-related frameworks already exist, each describing stimuli or boundary conditions of psychological processes in a flexible way that allows for continual updating that reflects changes in technology (e.g., Potosky's (2008) framework of assessment media or Ravid et al.'s (2020) framework of electronic performance monitoring). When we, as researchers, shift our focus from being correct (i.e., deductive research/model testing) to being inquisitive (i.e., inductive research/framework building), technological change becomes quite compatible with our duty to conduct relevant psychological research.

\section{Collaboration}

I-O psychologists can also produce timelier technology research by forming interdisciplinary partnerships. Researchers from the fields of I-O psychology and those from the fields of computer science, communication, political science, and economics are all jointly interested in the effects of technologies on individuals (e.g., Christensen \& Garfias, 2018; Dalal, \& Randall, 2017; Ma \& McGroarty, 2017; Treem et al., 2015), but they often run parallel lines of research without intertwining. Differences in the ways that various academic fields think about, speak about, and actually conduct scientific research introduce research opportunities rather than barriers. For instance, political science often emphasizes describing phenomena, while data science and psychology tend to emphasize predicting and explaining phenomena, respectively (König et al., 2020). In accordance with these different emphases, individuals in each field tend to develop unique languages and research methods to answer their research questions. An I-O psychologist may focus on reliability and validity for theory building and construct validation; a data scientist may focus on web scraping and machine learning for compiling and organizing Big Data; and a political scientist may focus on public trends for constructing multilevel models. 
These different languages and research approaches are complementary; an I-O psychologist's expertise in validation can make a data scientist's web scraping tool theoretically meaningful, a data scientist's machine learning expertise can support a political scientist's analysis of public records, and so on. Research on the potential for functional diversity (e.g., diversity of skills, experiences) to increase collaborative performance and creativity (Bantel, 1993; Bunderson, 2003; Harrison \& Klein, 2007) stems from our own field, with particularly prudent implications when it comes to technology research. In combination, researchers across various fields of study are able to answer research questions about new technologies much more quickly and more effectively than any one group could do alone.

I-O psychologists can take a number of steps to actualize these partnerships. Members of our community are actively engaged in conversations about how to best promote interdisciplinary collaboration for technology research (Gonzalez et al., 2019; König et al., 2020; Oswald et al., 2020). We view these conversations as comprising three major inter-related activities: learning, communicating, and planning.

Individuals more effectively work with one another when they are open to learning about each other's perspectives. As I-O psychologists, we should first identify areas for which our understanding of technology is lacking. For instance, other scholars have more expertise regarding the technological characteristics of new tools (e.g., computer processing), while others know more about how these tools influence individuals at varying levels of analysis (e.g., inside the human brain, across school districts, or in national economies). To start learning about these differences, we urge readers to seek existing primers and cross-disciplinary proposals related to technology (see Murray \& Antonakis (2019) for an introduction to organizational neuroscience or König et al. (2020) for advice on working with computer scientists). Other learning 
opportunities exist regarding methodologies — some fields regularly use tools like functional magnetic resonance imaging (fMRI) for data collection or Python for data analysis. Fortunately, plenty of online tutorials are readily available to I-O psychologists seeking an introduction to new data collection and analysis methods (e.g., see cbmm.mit.edu and ocw.mit.edu for resources regarding the basics of fMRI and Python). We refer interested readers to Oswald et al. (2020) for additional links to tutorials and other online content relevant to the study of technology in I-O psychology.

Learning about new content and methods makes us more effective cross-disciplinary communicators. We encourage I-O psychologists with a basic understanding of a new domain to seek low-stakes opportunities to actually engage with experts from other fields. Websites such as KDnuggets provide online forums and regular webinars that give users the opportunity to ask researchers from various domains questions about artificial intelligence, Big Data, and other data technologies. Such settings represent an excellent opportunity for I-O psychologists to identify and discuss any important technology problems shared across disciplines. At the same time, I-O psychologists should strive to create content that supports interdisciplinary communication. When sharing research with those from other disciplines, I-Os should communicate their ideas clearly, simply, and concisely; a variety of visualization tools exist to assist I-O psychologists in achieving these communication goals (Oswald et al. 2020).

Planning can help I-O psychologists anticipate and overcome obstacles that could potentially hinder future collaborations. Learning and communicating across disciplines can be quite challenging in practice, where I-O psychologists are faced with a number of resource constraints. For instance, some I-O psychologists may struggle to find job opportunities that support true collaboration with technology experts. Recently, Gonzalez and colleagues (2020) 
encouraged I-O psychologists to seek employment in companies focusing on artificial intelligence and machine learning as a means of advancing human knowledge of these technologies. In other organizations, I-O psychologists may benefit from clearly articulating the benefits of technology collaboration to their colleagues. Further, some I-O psychologists, particularly graduate students, may simply lack an awareness or an appreciation for collaborative research opportunities regarding technology. The Guidelines for Training and Education in Industrial-Organizational Psychology (2017) encourage faculty members to incorporate major workplace technology trends in their coursework. We agree with this suggestion and expand upon it to suggest that senior faculty should introduce their younger colleagues to non-I-O researchers in their network whenever appropriate. Doing so will ideally alleviate awareness constraints and help establish norms for cross-disciplinary collaboration among future generations of I-O psychologists.

\section{Dissemination}

Sharing our work in other venues and with other audiences further supports timelier technology research in the I-O psychology community. It is worth noting that an I-O researcher who completes a study in the winter would need to wait over a year to share these findings by adhering to SIOP's "fall submission" and "spring presentation” schedule. Although SIOP's peerreview process is quick in relation to that of most academic I-O journals, it remains possible that I-O psychologists lack an awareness of or an interest in other, timelier means of dissemination. While our study did not explicitly analyze I-O technology research outside of SIOP, we still urge I-O researchers to look beyond our own community and seek other audiences who can benefit from our work. 
Many opportunities for research dissemination exist in the form of conferences both within and outside of the I-O psychology community. From within, SIOP now hosts the Leading Edge Consortium to advance our knowledge of special topics that often relate to technology. Balancing out the typical spring schedule of the general SIOP conference, the Leading Edge Consortium generally occurs in the fall. The consortium brings together scientists and practitioners who share an interest in a hot topic, ranging from technology's uses during assessment, talent analytics, and coaching, among others. We encourage interested I-Os to attend events hosted by I-O psychologists and related fields (e.g., Society of Human Resource Management, Academy of Management, Society for Personality and Social Psychology) but recognize that we also need to share our voice in other fields, particularly those that may overlook the psychological effects of technology. In most areas of technology, high impact conferences occur on a more regular basis with published proceedings to encourage timely research dissemination. The Association for Computing Machinery, for example, hosts over 170 conferences, workshops, and symposia each year, and has published over 230,000 refereed papers. Other relevant avenues for technology research dissemination include the Institute of Electrical and Electronics Engineers (IEEE), in addition to more cross-disciplinary avenues such as the APA's annual Technology, Mind, and Society conference (TMS). Together, these events give I-O psychologists an opportunity to disseminate their technology research to multiple audiences and more regularly than once per year.

Beyond conferences, we urge I-O psychologists to make use of recent pushes for increased transparency in the publication process to disseminate technology research in a timely fashion. Outlets such as the Journal of Business and Psychology now offer results-blind submission processes (Kreamer \& Rogelberg, 2020), which supports technology research in that 
the review process is initiated before data collection is completed. Other peer-reviewed outlets such as PLOS ONE are open access and have a significantly shorter acceptance-to-publication time than traditional journals (Björk \& Solomon, 2013). In addition, other avenues such the Center for Open Science's PsyArXiv allows researchers to upload manuscripts prior to the peer review process. Collectively, these open science endeavors offer many opportunities beyond conferences for I-O psychologists to share technology research more quickly.

In addition to sharing our work with other researchers, we must also disseminate our findings to practitioners who interact with new technologies on a regular basis. In a recent discussion on talent identification, Chamorro-Premuzic and colleagues (2016) showed that human resource practitioners adopt technologies more quickly than academic I-O psychologists study them. Workers who interact with new technologies often experience unique challenges as a result of this lag. Consider trends toward artificial intelligence and Big Data, wherein practitioners can amass data on a wide variety of variables to predict desirable outcomes such as job performance. Absent from many of these predictions is a sound theory to explain why or how random variables predict an outcome. Thus, variables measured using new technologies often lack construct validity evidence (Hickman et al., 2019; Roth et al., 2016) and therefore produce unanticipated outcomes such as adverse impact (Gonzalez et al., 2019). To prevent such outcomes, we urge I-O psychologists to collaborate with their practicing colleagues when possible, to engage in scientist-practitioner sessions at SIOP and related conferences, and to practice effective communication with business leaders (see the communication suggestions above). In doing so, we are much better suited to identify and study the new technologies organizations are actually adopting.

\section{Creation}


Our final suggestion for I-O psychologists to produce timelier technology research is to actually create new technologies. As experts in human thought and behavior, I-O psychologists should play an active, rather than reactive, role in developing the tools that individuals will interact with on a regular basis. In our review, we identified several examples of I-O psychologists who used our science to produce a useful piece of technology for workers. Perhaps the most widely acknowledged examples are the many R packages and related scripts that I-O psychologists have created to aid professionals and researchers with data analysis (e.g., Dahlke \& Wiernik, 2019; Goebl et al., 2016). We also identified several examples of innovative technologies created to advance our knowledge of measurement and surveying. For example, I-O psychologists working within technology firms have used their voice to develop gamified situational judgment tests (e.g., AON's chatAssess). Academic I-Os are also involved in the creation of new technologies. One example is Tay (2020), who used research on survey design and implementation to create the experience sampling tool ExpiWell. Similarly, Waber (2011, 2020) used existing work on technology, social networks, and organizational design to help develop sociometric badges that measure conversational dynamics in social groups. We strongly urge other I-O psychologists to think similarly about the implications of their work; technology should not merely be a future research direction in our papers, but also an opportunity to use what we know to create tools that can directly benefit workers.

\section{Closing Thoughts}

Members of the I-O psychology community—ranging from academics to practitioners, undergraduates to $\mathrm{PhDs}$, and scholars of every domain — acknowledge that technology changes both what we do in our jobs and how we do it. In spite of this widespread agreement, we also tend to act as bystanders when it comes to understanding new technologies. Extending our 
research to a new, constantly evolving area may seem scary or uncertain, but with uncertainty comes opportunity. We encourage I-O psychologists to recognize the benefits of timely technology research as we find ourselves amidst the COVID-19 pandemic and beyond. The goal of science is not to be correct but rather to advance human knowledge of the world. At a time when technology research is arguably more important than ever, I-O psychologists are best suited to achieve this goal when we approach technology research with a strong desire for action, exploration, collaboration, dissemination, and creation. 


\section{References}

Abelson, R. (2020, March 11). Doctors and patients turn to telemedicine in the coronavirus outbreak. NYTimes. Retrieved from https://www.nytimes.com/2020/03/11/health/telemedicine-coronavirus.html

American Psychological Association. (2008). Industrial and organizational psychology. APA.org. Retrieved from https://www.apa.org/ed/graduate/specialize/industrial Association for Computing Machinery. Retrieved from https://www.acm.org/conferences

Bantel, K. A. (1993). Comprehensiveness of strategic planning: the importance of heterogeneity of a top team. Psychological Reports, 73(1), 35-49. https://doi.org/10.2466/pr0.1993.73.1.35

Bell, K. (2014, April 7). 72\% of Americans refuse Google Glass over privacy concerns: Report. Mashable. Retrieved from https://mashable.com/2014/04/07/google-glass-privacy/

Björk, B. C., \& Solomon, D. (2013). The publishing delay in scholarly peer-reviewed journals. Journal of Informetrics, 7(4), 914-923. https://doi.org/10.1016/j.joi.2013.09.001

Bond, S. (2020, April 3). A must for millions, Zoom has a dark side - And an FBI warning. NPR. Retrieved from https://www.npr.org/2020/04/03/826129520/a-must-for-millionszoom-has-a-dark-side-and-an-fbi-warning

Bowen, C., Davidson, S., \& Stevenor, B. A. (2019, April). Job applicants’ perceptions and reactions of hiring companies' social media policies. Poster presented at the 34th annual meeting of the Society for Industrial and Organizational Psychology, National Harbor, MD. 
Bowman, D. A., \& McMahan, R. P. (2007). Virtual reality: how much immersion is enough? Computer, 40(7), 36-43. https://doi.org/10.1109/MC.2007.257

Bricka, T., Schroeder, A. N., Hameed, S. (2020, June). Influencing the influencer: A proposed model of social media influencer effectiveness. Poster presented at the 35 th annual meeting of the Society for Industrial and Organizational Psychology, Austin, TX.

Brown, K. G., Ironside, T. M., Linn, C. F., \& Johnson, B. L. (2001, April). An inductive exploration of barriers to participation and completion of e-learning opportunities. In HR.COM: Human resource management strategies for the dot-com world. Symposium conducted at the 16th annual meeting of the Society for Industrial and Organizational Psychology, San Diego, CA.

Bunderson, J. S. (2003). Team member functional background and involvement in management teams: Direct effects and the moderating role of power centralization. Academy of Management Journal, 46(4), 458-474. https://doi.org/10.2307/30040638

Butina, B. (Producer). (2020, April 2). Stephanie Mockler on coaching leaders during COVID19. [Audio podcast]. Retrieved from https://podcasts.apple.com/us/podcast/stefaniemockler-on-coaching-leaders-during-covid-19/id1084104705?i=1000470373482

Campion, M. A. (2011). Distinguished Scientific Contributions Award: How to publish like heck and maybe even enjoy it. The Industrial-Organizational Psychologist, 49(2), 43-56.

Chamorro-Premuzic, T., Winsborough, D., Sherman, R. A., \& Hogan, R. (2016). New talent signals: Shiny new objects or a brave new world?. Industrial and Organizational Psychology, 9(3), 621-640. https://doi.org/10.1017/iop.2016.6

Chapman, D. S. \& Rowe, P. M. (1998, April). The influence of videoconference technology and interview structure on the recruiting function of the employment interview. Poster 
presented at the 13th annual meeting of the Society for Industrial and Organizational Psychology, Dallas, TX.

Christensen, D., \& Garfias, F. (2018). Can you hear me now? How communication technology affects protest and repression. Quarterly Journal of Political Science, 13(1), 89. https://doi.org/10.1561/100.00016129

Computer History Museum, Timeline of Computer History [Timeline]. (n.d.). Retrieved from http://www.computerhistory.org/timeline/.

Cummings, J. J., \& Bailenson, J. N. (2016). How immersive is enough? A meta-analysis of the effect of immersive technology on user presence. Media Psychology, 19(2), 272-309. https://doi.org/10.1080/15213269.2015.1015740

Curphy, G. \& Nilsen, D. (2020, April 1). Managing stress during COVID-19: The dark side of personality. [White paper]. Retrieved from https://www.siop.org/Research-

Publications/Items-of-Interest/ArtMID/19366/ArticleID/3443/Managing-Stress-DuringCOVID-19-The-Dark-Side-of-Personality

Dahlke, J. A., \& Wiernik, B. M. (2019). psychmeta: An R package for psychometric metaanalysis. Applied Psychological Measurement, 43(5), 415-416.

Dalal, D. K., \& Randall, J. G. (2017). Integrating technology into models of response behavior. Industrial and Organizational Psychology, 10(4), 680-687. https://doi.org/10.1017/iop.2017.76

DARPA, A Selected History of DARPA Innovation [Timeline]. (n.d.). Retrieved from https://www.darpa.mil/Timeline/index.html.

Dates and Events, Events Timeline: Technology Timeline [Timeline]. (n.d.). Retrieved from http://www.datesandevents.org/eventstimelines/12-technology-timeline.htm 
Dean, S. (2020, March 6). 'Can everyone mute?' Coronavirus means we must telecommute.

We're not ready. LATimes. Retrieved from

https://www.latimes.com/business/technology/story/2020-03-06/coronavirus-

$\underline{\text { telecommute-work-from-home }}$

Elgan, M. (2008, July 8). Why Google's 'Lively' is great for telecommuters. ComputerWorld.

Retrieved from https://www.computerworld.com/article/2478480/why-google-s--lively-is-great-for-telecommuters.html

Emani, C. K., Cullot, N., \& Nicolle, C. (2015). Understandable big data: a survey. Computer Science Review, 17, 70-81. https://doi.org/10.1016/j.cosrev.2015.05.002

Fletcher, S., Robinson, J., Nester, M. A., \& OLeary, B. (2000, April). Technology in the hiring process for U.S. Practitioner forum held at the 15 th annual meeting of the Society for Industrial and Organizational Psychology, New Orleans, LA.

Thompson, L. F., Mullins, A. K., Robinson, J. B., \& Halberstadt, J. B. (2010, April). Escreening: The consequences of using "smileys" when e-mailing prospective employers. Poster presented at the 25 th annual meeting of the Society for Industrial and Organizational Psychology, Atlanta, GA.

Freberg, K., Graham, K., McGaughey, K., \& Freberg, L. A. (2011). Who are the social media influencers? A study of public perceptions of personality. Public Relations Review, 37(1), 90-92. https://doi.org/10.1016/j.pubrev.2010.11.001

Gasparevic, D. (2018, August 14). Why virtual-reality training for employees is catching on. SHRM. Retrieved from https://www.shrm.org/resourcesandtools/hrtopics/technology/pages/why-virtual-reality-training-for-employees-is-catching-on.aspx 
Goebl, A. P., Jones, J. A., and Beatty, A. S. (2016). iopsych: Methods for industrial/organizational psychology. R package version 0.90 .

Goh, J., Truman, B., \& Barber, D. (2018, April). Investigating the role of cognitive load in virtual world training programs. Poster presented at the 33ed annual meeting of the Society for Industrial and Organizational Psychology, Chicago, IL.

Gonzalez, M. F., Capman, J. F., Oswald, F. L., Theys, E. R., \& Tomczak, D. L. (2019).

"Where's the IO?” Artificial intelligence and machine learning in talent management systems. Personnel Assessment and Decisions, 5(3),33-44. https://doi.org/10.25035/pad.2019.03.005

Google Glass (2020). Retrieved from https://www.google.com/glass/faq/

Graetz, K., Barlow, C., Prouix, N.,Odenweller, L., Weierman, S., Blankenship, C., \& Strazzo, D. (1999, April). Negotiation at a distance: Why you might want to use the telephone. Poster presented at the 14th annual meeting of the Society for Industrial and Organizational Psychology, Atlanta, GA.

Grant, A., M. [AdamMGrant] (2020, March 26). "Find a quiet room and close the door..." People mean well, but let's face it: the boundary between work and home has blurred. Here's to relaxing our expectations for virtual meetings. Interruptions are part of our new reality. We're all BBC dad now. \#ThursdayThoughts. [Tweet]. Retrieved from https://twitter.com/AdamMGrant/status/1243214784696406017

Greene, T. (2008, July 30). How secure is Skype, really? PCWorld. Retrieved from https://www.pcworld.com/article/149119/skype.html 
Haidar, S. S., Yankov, G. P., Kumar, S., Zheng, J. (2020, June). Using machine learning to classify assessment center text data. Poster presented at the 35 th annual meeting of the Society for Industrial and Organizational Psychology, Austin, TX.

Hambrick, D. C. (2007). The field of management's devotion to theory: Too much of a good thing? Academy of Management Journal, 50(6), 1346-1352. https://doi.org/10.5465/AMJ.2007.28166119

Harrison, D. A., \& Klein, K. J. (2007). What's the difference? Diversity constructs as separation, variety, or disparity in organizations. Academy of Management Review, 32(4), 11991228. https://doi.org/10.5465/AMR.2007.26586096

Harvey, D. (1989). The condition of postmodernity (Vol. 14). Oxford: Blackwell.

Hickman, L., Tay, L., \& Woo, S. E. (2019). Validity evidence for off-the-shelf language-based personality assessment using video interviews: Convergent and discriminant relationships with self and observer ratings. Personnel Assessment and Decisions, 5(3),12-20. https://doi.org/10.25035/pad.2019.03.003

Holmes, T. E. (2020, April 16). COVID-19 Crisis shines light on pros and cons of working remotely. Yahoo Finance. Retrieved from https://finance.yahoo.com/news/covid-19crisis-shines-light-155840632.html

Huvila, I. (2015). "We've got a better situation": The life and afterlife of virtual communities in Google Lively. Journal of Documentation, 71, 526-549. https://doi.org/10.1108/JD-092013-0116

Hype Cycle (n.d.). Gartner. Retrieved from https://www.gartner.com/en/informationtechnology/glossary/hype-cycle 
Kastrenakes, J. (2014, June 16). Google launches 'Glass at Work' program with five partners making apps for business. Retrieved from https://www.theverge.com/2014/6/16/5814980/google-glass-at-work-first-partners$\underline{\text { announced }}$

Keebler, J. (2017, April). Applying augmented reality in training - A brief history and future insight. In opportunities and challenges in electronic human resource management. Alternative session presented at the 32nd annual meeting of the Society for Industrial and Organizational Psychology, Orlando, FL.

Keeney, M. J., Halverson, K. C., Oster, E. L., Kegley, J. (2020, June). Optimizing and validating training technology selection. Poster presented at the 35th annual meeting of the Society for Industrial and Organizational Psychology, Austin, TX.

King University Online, Technology Through the Years Infographic [Timeline]. (n.d.). Retrieved from https://online.king.edu/technology-through-the-yearsinfographic/.

König, C. J., Demetriou, A. M., Glock, P., Hiemstra, A. M., Iliescu, D., Ionescu, C., ... \& Vartholomaios, I. (2020). Some advice for psychologists who want to work with computer scientists on big data. Personnel Assessment and Decisions, 6(1), 2.

Kreamer, L., \& Rogelberg, S. G. (2020). Using results-blind reviewing to support the peer review competency framework. Industrial and Organizational Psychology, 13(1), 2831. https://doi.org/10.1017/iop.2020.6

Kubisiak, U. C., Hanson, M. A., \& Borman, W. C. (1998, April). Job clustering using the O*NET. Symposium conducted at the 13th annual meeting of the Society for Industrial and Organizational Psychology, Dallas, TX. 
Landers, R. N. (2020, March 11). Trying to understand SIOP 2020 and coronavirus [Blog post]. Retrieved from http://neoacademic.com/2020/03/11/trying-to-understand-siop-2020and-coronavirus/

Landers, R. N., \& Behrend, T. S. (Chairs) (2011, April). Empirical evidence for emerging technology: MUVEs/Virtual worlds in HR. Symposium conducted at the 26th annual meeting of the Society for Industrial and Organizational Psychology, Chicago, IL.

Landers, R. N., \& Sackett, P. R. (2009, April). Applicant pool increases counter cheating in unproctored internet testing. Poster presented at the 24th annual meeting of the Society for Industrial and Organizational Psychology, New Orleans, LA.

Landers, R., \& Behrend, T. (2017). When are models of technology in psychology most useful? Industrial and Organizational Psychology, 10(4), 668-675. https://doi.org/10.1017/iop.2017.74

Levine, P. (Chair). (2014, May). Big data: From hype to practical realities. Panel discussion held at the 29th annual meeting of the Society for Industrial and Organizational Psychology, Honolulu, HI.

Liang, L. (2020, March 8). Millions of Chinese employees are working from home for the first time, as the nation tackles Covid-19. Will it change conservative corporate culture? $B B C$. Retrieved from https://www.bbc.com/worklife/article/20200309-coronaviruscovid-19-advice-chinas-work-at-home-experiment

Lim, A., Uy, M., Lim, V. (2008, April). An exploratory study of perceived flaming behaviors in Asia. Poster presented at the 23ed annual meeting of the Society for Industrial and Organizational Psychology, San Francisco, CA. 
Locke, E. A. (2007). The case for inductive theory building. Journal of Management, 33(6), 867890. https://doi.org/10.1177/0149206307307636

Ma, T., \& McGroarty, F. (2017). Social Machines: how recent technological advances have aided financialisation. Journal of Information Technology, 32(3), 234-250. https://doi.org/10.1057/s41265-017-0037-7

Massachusetts Institute of Technology (n.d.). MIT Technology Review. Retrieved from https://www.technologyreview.com/

McCullagh, D. (2008, June 9). How safe is instant messaging? A security and privacy survey. CNet. Retrieved from https://www.cnet.com/news/how-safe-is-instant-messaging-asecurity-and-privacy-survey/

McManus, M. A. \& Ferguson, M. W. (2002, April). Characteristics of internet recruits: An exploratory study. Poster presented at the 17 th annual meeting of the Society for Industrial and Organizational Psychology, Toronto, ON, Canada.

Morelli, N., Potosky, D., Arthur, W., \& Tippins, N. (2017). A call for conceptual models of technology in IO psychology: An example from technology-based talent assessment. Industrial and Organizational Psychology, 10(4), 634-653. https://doi.org/10.1017/iop.2017.70

Morrison, S. (2020, April 2). Just because you're working from home doesn't mean your boss isn't watching you. Vox. Retrieved from https://www.vox.com/recode/2020/4/2/21195584/coronavirus-remote-work-from-homeemployee-monitoring 
Murray, M. M., \& Antonakis, J. (2019), An introductory guide to organizational neuroscience. Organizational Research Methods, 22(1), 6-16. https://doi.org/10.1177/1094428118802621

Museum of Arts and Design, 3D Printing Timeline [Timeline]. (n.d.). Retrieved from https://madmuseum.org/sites/default/files/static/ed/3D\%20Printed\%20Timeline\%20Reso urce.pdf

Nassauer, S., \& Cutter, C. (2019, June 30). Walmart turns to VR to pick middle managers. The Wall Street Journal. Retrieved from https://www.wsj.com/articles/walmart-turns-to-vr-topick-middle-managers-11561887001

Offermann, L. R. \& Eller, S. (Chairs). (1999, April). Teams at a distance: Lessons learned and future prospects. Symposium conducted at the 14th annual meeting of the Society for Industrial and Organizational Psychology, Atlanta, GA.

Oswald, F. L., Behrend, T. S., Putka, D. J., \& Sinar, E. (2020). Big data in industrialorganizational psychology and human resource management: Forward progress for organizational research and practice. Annual Review of Organizational Psychology and Organizational Behavior, 7, 505-33. https://doi.org/10.1146/annurev-orgpsych-032117104553

Overland, M. A. \& Jarvis, W. (2020, March 15). Virtual happy hour anyone? Working from home but keeping connected. NPR. Retreived from https://www.npr.org/2020/03/15/815973389/virtual-happy-hour-anyone-working-fromhome-but-keeping-connected 
Paik, L. S., Li, X., Zhang, M., Zibell, M., Griffeth, R. W., Robinson, S. D. (2013, April). Biases in the context of hiring through LinkedIn. Poster presented at the 28th annual meeting of the Society for Industrial and Organizational Psychology, Houston, TX.

Pearlman, D. M., \& Gates, N. A. (2010). Hosting business meetings and special events in virtual worlds: a fad or the future? Journal of Convention \& Event Tourism, 11(4), 247-265. https://doi.org/10.1080/15470148.2010.530535

Pennic, F. (2014, July 3). Stanford University Medical School to deploy Google Glass to improve surgeon training. HIT Consultant. Retrieved from https://hitconsultant.net/2014/07/30/stanford-university-medical-school-to-deploygoogle-glass-to-improve-surgeon-training/\#.XpCqDJNKiu4

Pierce, C. A., \& Aguinis, H. (1997). Using virtual reality technology in organizational behavior research. Journal of Organizational Behavior, 18, 407-410. https://doi.org/10.1002/(SICI)1099-1379(199709)18:5<407::AID-JOB869>3.3.CO;2-G

Potosky, D. (2008). A conceptual framework for the role of the administration medium in the personnel assessment process. Academy of Management Review, 33(3), 629-648.

Quintero, V. C., \& Strickland, O. J. (2002, April). Technology during interviewing: Effects on applicant reactions to interview strategy. Poster presented at the 17 th annual meeting of the Society for Industrial and Organizational Psychology, Toronto, ON, Canada.

Ravid, D. M., Tomczak, D. L., White, J. C., \& Behrend, T. S. (2020). EPM 20/20: A Review, framework, and research agenda for electronic performance monitoring. Journal of Management, 46(1), 100-126. https://doi.org/10.1177/0149206319869435

Reuter, D. (2020, February 10). Here's how top companies are using VR to connect and train teams from around the world. Business Insider. Retrieved from 
https://www.businessinsider.com/how-top-companies-using-vr-connect-train-remoteteams-2020-2

Rivero, N. (2020, October 15). It took a pandemic to make QR codes a global sensation. Retrieved from https:/qz.com/1917661/qr-codes-are-finally-having-their-momentbecause-of-covid-19/

Roberts, D. R. (Chair). (2018, April). Virtual reality and augmented reality: An emerging area for I-O research and practice. Panel discussion held at the 33ed annual meeting of the Society for Industrial and Organizational Psychology, Chicago, IL.

Rogelberg, S. (2020, March 17). 10 quick tips to make remote meetings work-Leveraging the surprising science of meetings. [Video file]. Video posted to https://www.youtube.com/watch?v=gkoCNJVrd04\&feature=emb_title

Rosopa, P. J., Moore, A. F., Klinefelter, Z. P., Xoxakos, P. \& Watson, G. P. (2020, June). Machines learn to improve inputs-outputs: Why not I-O? Poster presented at the 35th annual meeting of the Society for Industrial and Organizational Psychology, Austin, TX.

Scarborough, D. J., \& Somers, M. J. (2008, April). Update on neural networks in I-O psychology. Maser tutorial presented at the 23ed annual meeting of the Society for Industrial and Organizational Psychology, San Francisco, CA.

Scarborough, D. J., Chambless, B., \& Weiner, J. A. (2006, May). Effects of cheating in unproctored internet-based testing: A Monte Carlo investigation. In S. T. Hunt (Chair), Empirical investigations of unproctored personality measures used for employee selection. Practice forum held at the 21 st annual meeting of the Society for Industrial and Organizational Psychology, Dallas, TX. 
Shockley, K. \& Clark, M. (2020, April 6). Work-family balance struggles in the time of COVID19. [White paper]. Retrieved from https://www.siop.org/Research-Publications/Itemsof-Interest/ArtMID/19366/ArticleID/3454/Work-Family-Balance-Struggles-in-the$\underline{\text { Time-of-COVID-19 }}$

Short, E. M., Weidner, N., \& Sirabian, M. A. (2017, April). Exploring workplace relevant correlates of World of Warcraft achievements. In R. N. Landers (Chair), Serious assessment games and gamified assessment: Emerging evidence. Symposium conducted at the 32nd annual meeting of the Society for Industrial and Organizational Psychology, Orlando, FL.

Simmons, D. (2005, March 11). It's cheap to talk, on the net. BBC. Retrieved from http://news.bbc.co.uk/2/hi/programmes/click_online/4339195.stm

Society for Industrial and Organizational Psychology, Inc. (2017). Guidelines for education and training in industrial-organizational psychology. Bowling Green, $\mathrm{OH}$.

Steinert, M., \& Leifer, L. (2010, July). Scrutinizing Gartner's hype cycle approach. In PICMET 2010 Technology Management for Global Economic Growth (pp. 1-13). IEEE.

Sydell, E. J., Boyce, A. S., Lahti, K., Landers, R. N., Mecca, J. T., \& Ross, R. A. (2017, April). Will technology make assessment obsolete? Alternative session conducted at the $32 \mathrm{nd}$ annual meeting of the Society for Industrial and Organizational Psychology, Orlando, FL.

Tay, L. (2020). ExpiWell. Retrieved from https://app.expiwell.com/

Todd, S. (1996). Going global: Desktop video conferencing with CU-SeeMe. Learning \& Leading with Technology, 24(1), 57-61. 
Treem, J. W., Dailey, S. L., Pierce, C. S., \& Leonardi, P. M. (2015). Bringing technological frames to work: How previous experience with social media shapes the technology's meaning in an organization. Journal of Communication, 65(2), 396-422. https://doi.org/10.1111/jcom.12149

Vandenberg, R. J., \& Connelly, C. E. (2014, May). Using MPlus for structural equation modeling in I-O research. Seminar held at the 29th annual meeting of the Society for Industrial and Organizational Psychology, Honolulu, HI.

Waber, B. (2011). Understanding the link between changes in social support and changes in outcomes with the sociometric badge [Unpublished doctoral dissertation]. Massachusetts Institute of Technology.

Waber, B. (2020, April). Measuring indicators of organizational health and their impacts on productivity and employee attrition. [White paper]. Retrieved from humanyze.com/wpcontent/uploads/measuring-health-impacts-on-productivity-employee-attritionwhitepaper.pdf

Waber, B., Impelman, K., \& Shockley, K. M. (2014, May). Theme track: Technology meets application. Special event held at the 29th annual meeting of the Society for Industrial and Organizational Psychology, Honolulu, HI.

Woo, S. E. (2020, June). Inductive and abductive approaches to science. In S. McAbee, F. Guo, \& A. Samo (Chairs), Teaching big data methods in I-O graduate curriculum 3.0. Symposium conducted at the 35th annual meeting of the Society for Industrial and Organizational Psychology, Austin, TX. 
Woo, S. E., O'Boyle, E. H., \& Spector, P. E. (2017). Best practices in developing, conducting, and evaluating inductive research. Human Resource Management Review, 27(2), 255264. https://doi.org/10.1016/j.hrmr.2016.08.004

Wright, N. A., \& Gloss, A. E. (2015, April). O*NET and the changing world of work. Poster presented at the 30th annual meeting of the Society for Industrial and Organizational Psychology, Philadelphia, PA.

Zakon, Robert, H., Hobbes' Internet Timeline 25 [Timeline]. (1993-2018). Retrieved from https://www.zakon.org/robert/internet/timeline/ 
Figure 1. Gartner's Hype Cycle.

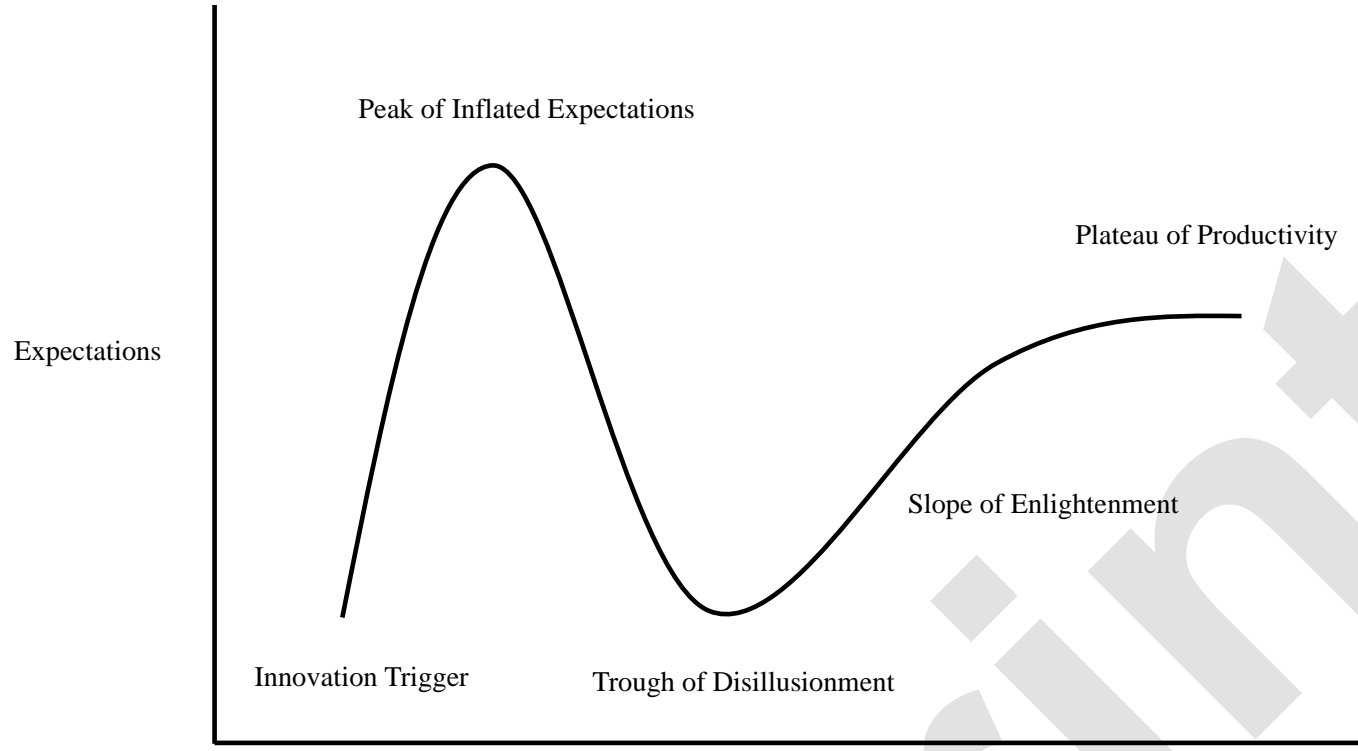

Time 